\title{
Status of Bone Mineral Density in Children with Type 1 Diabetes Mellitus and Its Related Factors
}

\author{
Fatemeh Sayarifard, ${ }^{1,2,3}$ Molood Safarirad, ${ }^{2}$ Ali Rabbani, ${ }^{1,2,3}$ Azadeh Sayarifard,,${ }^{4,}$ Vahid Ziaee, ${ }^{2,3,5}$ Aria \\ Setoodeh, ${ }^{1,2,3}$ and Parastoo Rostami $i^{1,2,3}$ \\ ${ }^{1}$ Growth and Development Research Center, Tehran University of Medical Sciences, Tehran, Iran \\ ${ }^{2}$ Children's Medical Center, Pediatric Center of Excellence, Tehran, Iran \\ ${ }^{3}$ Department of Pediatrics, Tehran University of Medical Sciences, Tehran, Iran \\ ${ }^{4}$ Center for Academic and Health Policy, Tehran University of Medical Sciences, Tehran, Iran \\ ${ }^{5}$ Pediatric Rheumatology Research Group, Rheumatology Research Center, Tehran University of Medical Sciences, Tehran, Iran \\ "Corresponding author: Azadeh Sayarifard, Growth and Development Research Center, Children's Medical Center, Center for Academic and Health Policy, Tehran University of \\ Medical Sciences, Tehran, Iran. Tel: +98-2161475, E-mail: drsayarifard@gmail.com
}

Received 2016 September 21; Revised 2017 March 11; Accepted 2017 April 07.

\begin{abstract}
Background: Type 1 Diabetes mellitus (DM) causes changes in bone mineral density (BMD).

Objectives: The aim of this study was to evaluate BMD in children with type 1DM and predictive factors of BMD loss in these patients. Methods: This cross-sectional study was conducted on 112 children with type 1 DM referrtd to children's medical center in Tehran, Iran during 2015 and 2016. Serum levels of hemoglobin A1c (HbA1c), Insulin-like growth factor 1(IGF-1), 25-hydroxy vitamin D (25(OH) D), calcium, phosphorus, parathyroid hormone (PTH), alkaline phosphates (ALP), Fasting blood sugar (FBS) was recorded. Lumbar spinal BMD (L1-L4) was measured in all patients by dual energy X-ray absorptiometry (DEXA). A BMD Z-score of $\geq-1$ was accepted as normal; between -1 and -2 , in the low range of normality; and $\leq-2$, low BMD. Bone mineral content (BMC) was calculated by DEXA and recorded.

Results: Median age was 12.5 (4 - 14) years. Low BMD and BMD in the low range of normality were diagnosed in 17 (15.2\%) and 25(22.3\%) of patients, respectively. There was a significant correlation between $\mathrm{BMD}$ and patient age $(\mathrm{P}<0.001)$, age of onset of diabetes $(\mathrm{P}<$ 0.001), IGF-1 $(\mathrm{P}=0.002)$, HbA1c $(\mathrm{P}=0.001)$ and PTH $(\mathrm{P}=0.040)$ but only HbA1c increased level significantly predicted reduction of BMD.

Conclusions: Glycemic control in children with type I diabetes is mainly predictor of changes in BMD and the changes in BMD were observed mainly in older ages and is independent of gender.
\end{abstract}

Keywords: Type 1 Diabetes mellitus, Bone Mineral Density, Children

\section{Background}

Osteoporosis is a type of skeletal diseases characterized by reduced bone density, integrity and increased risk of fracture (1-3). Osteoporosis, which is usually asymptomatic until a fracture occurs, is known as an alarming health problem throughout the world (4). Given the importance and high incidence of osteoporosis and bone fractures in patients with type $1 \mathrm{DM}$, researchers investigate different pathological mechanisms that reduce bone density in these patients (5-8). Bone marrow derived endothelial progenitor cells (EPCs) play an important role in bone repair, and diabetes leads to decreased expression of these cells through different paths, which ultimately reduces ossification at the fracture site (9).

In patients with type $1 \mathrm{DM}$, disruption in formation of bone trabeculation is due to deficiency of insulin and IGF-1, which leads to reduced bone mass. Simultaneous companion of autoimmune diseases and diabetes may double the risk of osteoporosis in these patients (10). In addition to influencing the pathophysiology on bone diseases caused by diabetes, bone density disorder in type $1 \mathrm{DM}$ is also influenced by genetic factors (11). Also, increasing risk of fractures has been reported in diabetic patients treated with insulin drugs than non-insulin drugs (12). Considering importance of osteoporosis in the individual's activity and increased risk of pathological fractures in the future, determining prevalence and risk factors of the problem in children with type $1 \mathrm{DM}$ and necessary treatments for its reduction is essential (13). Previous studies showed that type 1 DM causes reduction of bone density and ossification markers and increasing bone loss markers, and BMD is a good indicator for detecting changes in bone quality (14-20).

Given that most previous studies have been conducted on adults, further studies on diabetes and its effect on bone, particularly in childhood are required (21). Accord- 
ing to our knowledge there has been no published study on status of bone density in children with type 1 DM in Iran so far. Therefore we designed this study to investigate BMD status and its related factors in children with type 1 diabetes referring to Children's medical center as one of the largest referral pediatric centers in Iran.

\section{Methods}

This study was cross-sectional. The study was approved by ethics committee of Tehran University of Medical Sciences (code: IR.TUMS.REC.1395.2457).

Research population included children with type $1 \mathrm{DM}$ referring to children's medical center, a referral university affiliated hospital with 400 beds in Tehran, Iran, during 2015 - 2016.

Considering the diabetic children with low BMD as 10\% (21), $\alpha=0.0 .5$ and $\beta=0.8$, sample size was estimated 100 using following formula:

$n=\frac{z_{1-\frac{\alpha}{2}}^{2} p q}{d^{2}}$

It was a convenience sampling. Enrolled patients were taken from those being followed up for type 1 DM by clinic for endocrinology and diabetes in children's medical center, based on inclusion and exclusion criteria and after obtaining informed consent from their guardians.

Inclusion criteria included age above 4 years and type 1 diabetes with at least 3 years after its diagnosis.

Exclusion criteria included diseases affecting bone density, such as untreated hypothyroidism, hyperparathyroidism, intestinal malabsorption, celiac disease, inflammatory bowel disease, certain bone or joint diseases and history of bone fracture, liver disease, kidney disease, long term use of corticosteroids, and consumption of drugs that impact bone metabolism.

Age, height, weight, pubertal status, age at onset of diabetes, duration of diabetes, types of insulin therapy including regular, neutral protamine hagedorn (NPH) or LantusNovo rapid , daily prescribed insulin dose and daily calcium intake were recorded in all patients.

Height and weight measurements were done using a stadiometer (accuracy: 1 millimeter) and Seca balance (accuracy: 100 grams), respectively. Body mass index (BMI) was calculated as weight $(\mathrm{kg}) /$ height $^{2}\left(\mathrm{~m}^{2}\right)$.

Serum level of HbA1c was considered as glycemic control in the last three months and average values of the last three HbA1c measurements was recorded. Blood samples of patients after 10-hour fasting were collected in the morning, and Serum 25(OH)D, calcium, phosphorus, PTH, alkaline phosphatase, FBS, IGF-1 and HbA1c were measured using high-performance liquid chromatography with automated analyzer in the laboratory of children's medical center. Average hours of moderate to vigorous physical activity of the children within the last 7 days were recorded according to parents' information. Bone age was determined using left hand and wrist radiography.

Lumbar spinal BMD (L1-L4) was measured in all patients by dual energy X-ray absorptiometry (DEXA) device (DMS Stratos, France, serial number: J1201SD277) available in imaging center of children's medical center. Calibration was performed according to the instructions of software and device manufacturer. BMD values were determined as $\mathrm{g} / \mathrm{cm}^{2}$. These values were compared to $\mathrm{Z}$ score for age and gender in normal population. To investigate the relationship between BMD and other variables, BMD measures in patients were divided into three groups. A BMD Z-score of $\geq-1$ was accepted as normal; between -1 and -2 , in the low range of normality; and $\leq-2$, low BMD (21). Bone mineral content (BMC) was calculated by DEXA.

\subsection{Statistical Analysis}

SPSS 18 software was used for data analysis. The Kolmogorov-Smirnov(K-S) test was used for testing of normality of the distribution. In case of normal data distribution, parametric tests, and in case of non-normal distribution, non-parametric tests were used. Qualitative variables were analyzed using Chi square test and quantitative variables were analyzed using one way ANOVA or Kruskal Wallis. Correlation between variables was measured using Pearson correlation analysis. Multivariate linear regression model was used to predict the value of factors related to BMD reduction. Significance level was considered as $\mathrm{P}$ value $<0.05$ in all analyses.

\section{Results}

We assessed 123 patients for eligibility in this study. Three of whom were excluded due to celiac disease, 2 untreated hypothyroidism, 1 intestinal malabsorption, 1 history of bone fracture, 1 liver disease, 1 kidney disease and 2 long term use of corticosteroids. Finally 112 patients with type $1 \mathrm{DM}$ were included in the study.

Fifty seven (50.9\%) were female. Median age was 12.5 (4 -14) years.

Low BMD and BMD in the low range of normality were diagnosed in $17(15.2 \%)$ and 25 (22.3\%) of patients, respectively.

The characteristics of three groups (low BMD, BMD in the low range of normality and normal BMD) are given in Table 1. Information on comparison of three groups is given in Table 2 in terms of paraclinical variables. 
Table 1. Basic Characteristic of Low BMD, BMD in the Low Range of Normality and Normal BMD Groups ${ }^{\mathrm{a}}$

\begin{tabular}{|c|c|c|c|c|}
\hline Variable & Low BMD, $(\mathbf{n}=\mathbf{1 7})$ & BMD in the Low Range of Normality $(n=25)$ & Normal BMD $(n=70)$ & P Value \\
\hline Gender (female / male) & $8 / 9$ & $17 / 8$ & $32 / 38$ & 0.151 \\
\hline Age (year) & 14 & 13 & 11 & $0.015^{\mathrm{b}}$ \\
\hline $\operatorname{BMI}\left(\mathrm{kg} / \mathrm{m}^{2}\right)$ & $19.44 \pm 3.16$ & $18.72 \pm 3.22$ & $18.94 \pm 3.33$ & 0.619 \\
\hline Pubertal status (prepubertal/pubertal) & $4 / 13$ & $4 / 21$ & $14 / 56$ & 0.828 \\
\hline Age of onset of diabetes (year) & 7 & 8 & 6.8 & $0.002^{\mathrm{b}}$ \\
\hline Duration of diabetes (year) & $5.17 \pm 3.21$ & $3.98 \pm 0.95$ & $4.92 \pm 1.88$ & 0.113 \\
\hline Type of treatment (NPH - Regular / Lantus - Novo ) & $12 / 5$ & $19 / 6$ & $45 / 25$ & 0.541 \\
\hline Dose of insulin $(u / k g / d)$ & $1.08 \pm 0.21$ & $0.88 \pm 0.24$ & $0.87 \pm 0.19$ & $0.004^{\mathrm{b}}$ \\
\hline Physical activity (hour/week) & 4 & 4 & 2 & 0.449 \\
\hline
\end{tabular}

${ }^{a}$ Data are expressed as mean $\pm \mathrm{SD}$ (for normal distribution), Median (for non-normal distribution) or number of patients.

${ }^{\mathrm{b}} \mathrm{P}$ value $<0.05$ considered to be significant.

Table 2. Paraclinical Variables of Low BMD, BMD in the Low Range of Normality and Normal BMD Groups ${ }^{\mathrm{a}}$

\begin{tabular}{|c|c|c|c|c|}
\hline Variable & $\operatorname{Low} \operatorname{BMD}(\mathbf{n}=17)$ & BMD in the Low Range of Normality $(n=25)$ & Normal BMD $(n=70)$ & PValue \\
\hline FBS $(\mathbf{m g} / \mathbf{d L})$ & 209 & 169 & 196.5 & 0.143 \\
\hline IGF-1 (ng/mL) & $301.61 \pm 99.42$ & $276.04 \pm 129.06$ & $226.74 \pm 138.32$ & $0.032^{\mathrm{b}}$ \\
\hline HbA1c (\% ) & $9.83 \pm 1.51$ & $8.66 \pm 1.05$ & $8.11 \pm 0.94$ & $<0.001^{\mathrm{b}}$ \\
\hline Calcium (mg/dL) & $9.38 \pm 0.70$ & $9.29 \pm 0.32$ & $9.45 \pm 0.49$ & 0.166 \\
\hline Phosphorus (mg/dL) & 4.8 & 4.5 & 4.9 & 0.578 \\
\hline PTH $(\mathrm{pg} / \mathrm{mL})$ & $27.81 \pm 6.88$ & $27.27 \pm 7.48$ & $26.13 \pm 5.68$ & 0.466 \\
\hline $25(\mathrm{OH}) \mathrm{D}(\mathrm{ng} / \mathrm{mL})$ & $19.16 \pm 5.83$ & $33.00 \pm 15.08$ & $27.14 \pm 12.84$ & $0.002^{\mathrm{b}}$ \\
\hline Alkaline Phosphatase (IU/L) & $511.47 \pm 142.64$ & $556.80 \pm 156.50$ & $552.06 \pm 195.74$ & 0.617 \\
\hline Bone age (year) & 13.5 & 12.5 & 11 & $0.031^{\mathrm{b}}$ \\
\hline BMC $(\mathbf{g r} / \mathbf{c m})$ & $27.62 \pm 7.11$ & $27.29 \pm 7.77$ & $27.77 \pm 12.29$ & 0.764 \\
\hline
\end{tabular}

${ }^{\mathrm{a}}$ Data are expressed as mean $\pm \mathrm{SD}$ (for normal distribution) or median (for non-normal distribution).

${ }^{\mathrm{b}} \mathrm{P}$ value $<0.05$ considered to be significant.

IGF-1 level was significantly lower in normal BMD group $(\mathrm{P}=0.032)$. HbA1c was significantly different in three groups and BMD was reduced by increasing amount of HbA1c $(P<0.001)$. Serum vitamin D level represented a substantial reduction in the low BMD group $(\mathrm{P}=0.002)$. Bone age was lower in normal BMD group $(\mathrm{P}=0.031)$. Three groups did not show significant statistical difference for BMI, FBS, serum calcium, phosphorus, alkaline phosphatase, PTH and average BMC.

There was a correlation between amount of BMD and patient age (Pearson correlation $=-0.330, \mathrm{P}<0.001$ ), age of onset of diabetes (Pearson correlation $=-0.389, \mathrm{P}<0.001$ ), IGF-1 (Pearson correlation $=-0.287, \mathrm{P}=0.002)$, HbA1c (Pearson correlation $=-0.298, \mathrm{P}=0.001)$ and PTH (Pearson correlation $=-0.196, \mathrm{P}=0.040)$. Finally variable of age, $25(\mathrm{OH})$ D, HbA1c, IGF-1 and PTH, which had significant relationship with BMD in the above analysis, were entered in multivariate linear regression model, and only HbA1c increased level significantly predicted reduction of BMD.

\section{Discussion}

Along with previous studies on relationship between bone density changes, especially bone density reduction and type $1 \mathrm{DM}$, current study aimed at evaluating these changes with predictive factors of bone density reduction in this group of patients. In the current work, first it was found that there is significant relationship between BMD status of patients (three groups) and some characteristics such as age, age of onset of diabetes, as well as some paraclinical parameters like IGF-1, HbA1c, 25(OH) D, and bone 
Table 3. Effect of age, HbAlc, IGF-1, Vitamin D and PTH on BMD Status Changes ${ }^{\mathrm{a}}$

\begin{tabular}{|c|c|c|c|c|c|c|}
\hline \multirow[t]{2}{*}{ Variable } & \multirow[t]{2}{*}{ B } & \multirow[t]{2}{*}{ Std. Error } & \multirow[t]{2}{*}{ Beta } & \multirow[t]{2}{*}{ P Value } & \multicolumn{2}{|c|}{ Confidence Interval (95\%) } \\
\hline & & & & & Lower Bound & Upper Bound \\
\hline Age & -0.070 & 0.062 & -0.130 & 0.261 & -0.193 & 0.053 \\
\hline IGF1 & -0.002 & 0.001 & -0.200 & 0.079 & -0.004 & 0.000 \\
\hline HBA1c & -0.320 & 0.102 & -0.288 & 0.002 & -0.522 & -0.119 \\
\hline Vitamin D & -0.008 & 0.009 & -0.077 & 0.388 & -0.026 & 0.010 \\
\hline PTH & -0.032 & 0.019 & -0.146 & 0.097 & -0.070 & 0.006 \\
\hline
\end{tabular}

${ }^{\mathrm{a}}$ Dependent variable: bone mineral density.

age. In correlation analysis, inverse relationship was observed between BMD and patient's age, age of onset of diabetes as well as metabolic indexes related to diabetes type 1 including HbA1c, IGF-1 and PTH.

However, only HbA1c increased level significantly predicted reduction of BMD in multivariate regression model among all mentioned factors.

Findings of the current study can be contemplated in several points. First, the main predictor of BMD reduction and increased risk of osteoporosis is actually glycemic control in these patients, which is related to HbA1c. Second, other variables such as current fasting blood sugar and levels of calcium, phosphorus, and alkaline phosphatase were not able to predict BMD reduction. It seems reduction in BMD is a gradual process, and it is actually mostly affected by the control process of diabetes rather than acute and immediate changes in the above variables. Also with increasing age, duration of diabetes was longer and the risk of BMD reduction in patients went up. On the other hand, unlike some of the studies, where these changes are more visible in one of the two sexes $(22,23)$, change in BMD is mostly influenced by age of patients rather than gender of patients.

The finding on higher bone age and IGF-1 in Low BMD group may be due to older age of patients in this group in our study.

In the study by Loureiro, BMD was lower in diabetic patients and there was an inverse relationship between BMD and blood glucose levels and HbA1c (24); this relationship was observed only with HbA1c, and not with blood glucose levels in our study.

In the study by Onder, no significant difference was observed in terms of Vitamin D level and PTH among low BMD, BMD in the low range of normality, and normal BMD groups (21), which is inconsistent with findings in the current study.

In Heilman's work, lumbar BMD was significantly lower in diabetic children than non-diabetic children. This difference was mainly observed in boys rather than girls. In diabetic group, an inverse relationship was found between BMD and HbA1c (25). Although the observed inverse relationship was consistent with our study, gender difference is not consistent with the current study.

In Karagüzel's study, children with diabetes had lower serum calcium levels, PTH, osteocalcin and 25(OH) D levels were higher, but BMD amount had no relationship with the duration of illness or metabolic control in diabetic patients (26), which was not in line with our study.

In our study, vitamin D levels were significantly lower in low BMD group. Studies by Tahrani, Bucan and Svoren similarly showed deficiency in vitamin $\mathrm{D}$ in patients with diabetes (27-29). Vitamin D deficiency mechanism in children is different (30) and in patients with diabetes type 1 it includes genetic susceptibility factors, accompanying albuminuria or renal excretion of vitamin $\mathrm{D}$ and/or its metabolites $(28,31)$.

In a study by Leger, in girls with diabetes, BMD values were lower than in healthy girls, but this difference was not observed in boys (22). In Vazquez's study results showed that boys with diabetes had lower BMD than their peers in the control group (23). Again this difference in results by gender was not consistent with our study.

In general, it seems that the differences between metabolic and serum markers of diabetes type 1 and BMD values can be affected by various factors of which the most important are differences in the techniques used for measuring markers, inclusion and exclusion criteria, confounding factors and genetic differences between populations.

One of the limitations in the current study was that the study was conducted only in one center, our subjects were selected because of their convenient accessibility and proximity to the researchers so the findings cannot be generalized to all diabetic children, although children's medical center in Tehran is one of the largest pediatric referral centers in Iran, and almost patients from across the country 
refer to these center. Thus, it is suggested that future investigations in this relation be designed as longitudinal and multi-center studies.

Overall it can be concluded that firstly glycemic control in children with type I diabetes is mainly predictor of changes in BMD, and secondly, the changes in BMD were observed mainly in older ages and is independent on gender.

\section{Acknowledgments}

We are very thankful to all patients and co-workers for their assistance in this study. The authors have no conflicts of interest to declare.

\section{References}

1. Kurra S, Siris E. Diabetes and bone health: the relationship between diabetes and osteoporosis-associated fractures. Diabetes Metab Res Rev. 2011;27(5):430-5. doi:10.1002/dmrr.1197. [PubMed: 21432981].

2. Schwartz AV, Sellmeyer DE. Diabetes, fracture, and bone fragility. Curr Osteoporos Rep. 2007;5(3):105-11. [PubMed: 17925191].

3. Janghorbani M, Van Dam RM, Willett WC, Hu FB. Systematic review of type 1 and type 2 diabetes mellitus and risk of fracture. Am JEpidemiol. 2007;166(5):495-505. doi: 10.1093/aje/kwm106. [PubMed: 17575306].

4. Lampropoulos CE, Papaioannou I, D'Cruz DP. Osteoporosis-a risk factor for cardiovascular disease? Nat Rev Rheumatol. 2012;8(10):587-98. doi:10.1038/nrrheum.2012.120. [PubMed: 22890244].

5. Hamann C, Kirschner S, Gunther KP, Hofbauer LC. Bone, sweet bone-osteoporotic fractures in diabetes mellitus. Nat Rev Endocrinol. 2012;8(5):297-305. doi: 10.1038/nrendo.2011.233. [PubMed: 22249517].

6. Wongdee $\mathrm{K}$, Charoenphandhu N. Osteoporosis in diabetes mellitus: Possible cellular and molecular mechanisms. World J Diabetes. 2011;2(3):41-8. doi: 10.4239/wjd.v2.i3.41. [PubMed: 21537459].

7. Sealand R, Razavi C, Adler RA. Diabetes mellitus and osteoporosis. Curr Diab Rep. 2013;13(3):411-8. doi: 10.1007/s11892-013-0376-x. [PubMed: 23471742].

8. Montagnani A, Gonnelli S, Alessandri M, Nuti R. Osteoporosis and risk of fracture in patients with diabetes: an update. Aging Clin Exp Res. 2011;23(2):84-90. [PubMed: 21743287].

9. Gurav AN. Advanced glycation end products: a link between periodontitis and diabetes mellitus? Curr Diabetes Rev. 2013;9(5):355-61. [PubMed: 23845077].

10. Rakel A, Sheehy O, Rahme E, LeLorier J. Osteoporosis among patients with type 1 and type 2 diabetes. Diabetes Metab. 2008;34(3):193-205. doi:10.1016/j.diabet.2007.10.008. [PubMed: 18308607].

11. Bid HK, Konwar R, Aggarwal CG, Gautam S, Saxena M, Nayak VL, et al. Vitamin D receptor (FokI, BsmI and TaqI) gene polymorphisms and type 2 diabetes mellitus: a North Indian study. Indian J Med Sci. 2009;63(5):187-94. doi: 10.4103/0019-5359.53164. [PubMed: 19584489].

12. Marchetti P, Lupi R, Bugliani M, Kirkpatrick CL, Sebastiani G, Grieco FA, et al. A local glucagon-like peptide 1(GLP-1) system in human pancreatic islets. Diabetologia. 2012;55(12):3262-72. doi: 10.1007/s00125-0122716-9. [PubMed: 22965295].

13. Khoshhal KI. Childhood osteoporosis. J Taibah Uni Med Sci. 2011;6(2):61-76.

14. Kindblom JM, Ohlsson C, Ljunggren O, Karlsson MK, Tivesten A, Smith $\mathrm{U}$, et al. Plasma osteocalcin is inversely related to fat mass and plasma glucose in elderly Swedish men. J Bone Miner Res. 2009;24(5):785-91. doi: 10.1359/jbmr.081234. [PubMed: 19063687].
15. Gerdhem P, Isaksson A, Akesson K, Obrant KJ. Increased bone density and decreased bone turnover, but no evident alteration of fracture susceptibility in elderly women with diabetes mellitus. Osteoporos Int. 2005;16(12):1506-12. doi: 10.1007/s00198-005-1877-5. [PubMed: 15824889].

16. Gennari L, Merlotti D, Valenti R, Ceccarelli E, Ruvio M, Pietrini MG, et al. Circulating sclerostin levels and bone turnover in type 1 and type $2 \mathrm{di}$ abetes. J Clin Endocrinol Metab. 2012;97(5):1737-44. doi: 10.1210/jc.20112958. [PubMed: 22399511].

17. Schmidt-Bleek K, Schell H, Lienau J, Schulz N, Hoff P, Pfaff M, et al. Initial immune reaction and angiogenesis in bone healing. J Tissue Eng Regen Med. 2014;8(2):120-30. doi: 10.1002/term.1505. [PubMed: 22495762].

18. Menegazzo L, Albiero M, Avogaro A, Fadini GP. Endothelial progenitor cells in diabetes mellitus. Biofactors. 2012;38(3):194-202. doi: 10.1002/biof.1016. [PubMed: 22488933].

19. Tsentidis C, Gourgiotis D, Kossiva L, Marmarinos A, Doulgeraki A, Karavanaki K. Sclerostin distribution in children and adolescents with type 1 diabetes mellitus and correlation with bone metabolism and bone mineral density. Pediatr Diabetes. 2016;17(4):289-99. doi: 10.1111/pedi.12288. [PubMed: 26094958].

20. Pan $\mathrm{H}, \mathrm{Wu} \mathrm{N}$, Yang T, He W. Association between bone mineral density and type 1 diabetes mellitus: a meta-analysis of cross-sectional studies. Diabetes Metab Res Rev. 2014;30(7):531-42. doi: 10.1002/dmrr.2508. [PubMed: 24376190].

21. Onder A, Cetinkaya S, Tunc O, Aycan Z. Evaluation of bone mineral density in children with type 1 diabetes mellitus. J Pediatr Endocrinol Metab. 2013;26(11-12):1077-81. doi: 10.1515/jpem-2012-0369. [PubMed: 24114897].

22. Leger J, Marinovic D, Alberti C, Dorgeret S, Chevenne D, Marchal $\mathrm{CL}$, et al. Lower bone mineral content in children with type 1 diabetes mellitus is linked to female sex, low insulin-like growth factor type I levels, and high insulin requirement. J Clin Endocrinol Metab. 2006;91(10):3947-53. doi: 10.1210/jc.2006-0711. [PubMed: 16849406].

23. Vazquez Gamez MA, Marin Perez JM, Montoya Garcia MJ. Evolution of bone mass in children and adolescents with type 1 diabetes mellitus. Medicina Clinica. 2008;130(14):526-30.

24. Loureiro MB, Ururahy MA, Freire-Neto FP, Oliveira GH, Duarte VM, Luchessi $\mathrm{AD}$, et al. Low bone mineral density is associated to poor glycemic control and increased OPG expression in children and adolescents with type 1 diabetes. Diabetes Res Clin Pract. 2014;103(3):452-7. doi: 10.1016/j.diabres.2013.12.018. [PubMed: 24529565].

25. Heilman K, Zilmer M, Zilmer K, Tillmann V. Lower bone mineral density in children with type 1 diabetes is associated with poor glycemic control and higher serum ICAM-1 and urinary isoprostane levels. $J$ Bone Miner Metab. 2009;27(5):598-604.doi:10.1007/s00774-009-00764. [PubMed: 19373518].

26. Karaguzel G, Akcurin S, Ozdem S, Boz A, Bircan I. Bone mineral density and alterations of bone metabolism in children and adolescents with type 1 diabetes mellitus. JPediatr Endocrinol Metab. 2006;19(6):805-14. [PubMed: 16886588].

27. Svoren BM, Volkening LK, Wood JR, Laffel LM. Significant vitamin $\mathrm{D}$ deficiency in youth with type 1 diabetes mellitus. $J \mathrm{Pe}$ diatr. 2009;154(1):132-4. doi: 10.1016/j.jpeds.2008.07.015. [PubMed: 19187735].

28. Bucan K, Ivanisevic M, Zemunik T, Boraska V, Skrabic V, VatavukZ, et al. Retinopathy and nephropathy in type 1 diabetic patients-association with polymorphysms of vitamin D-receptor, TNF, Neuro-D and IL-1 receptor 1 genes. Coll Antropol. 2009;33 Suppl 2:99-105. [PubMed: 20120526].

29. Tahrani AA, Ball A, Shepherd L, Rahim A, Jones AF, Bates A. The prevalence of vitamin $\mathrm{D}$ abnormalities in South Asians with type 2 diabetes mellitus in the UK. Int J Clin Pract. 2010;64(3):351-5. doi: 10.1111/j.17421241.2009.02221.x. [PubMed: 19863680].

30. Motlaghzadeh Y, Sayarifard F, Allahverdi B, Rabbani A, Setoodeh A, Sayarifard A, et al. Assessment of Vitamin D Status and Response to 
Vitamin D3 in Obese and Non-Obese Iranian Children. J Trop Pediatr. 2016;62(4):269-75. doi: 10.1093/tropej/fmv091. [PubMed: 26995012].

31. Diaz VA, Mainous AG 3rd, Carek PJ, Wessell AM, Everett CJ. The association of vitamin D deficiency and insufficiency with diabetic nephropathy: implications for health disparities. J Am Board Fam Med. 2009;22(5):521-7. doi: 10.3122/jabfm.2009.05.080231. [PubMed: 19734398]. 